This is a self-archived - parallel published version of this article in the publication archive of the University of Vaasa. It might differ from the original.

\title{
Evaluating Heat Current through Concrete Crush for Heat Storing Application : a preliminary study using polynomial fitting for heat current curves
}

Author(s): Martinkauppi, Jaana Birgitta; Hiltunen, Erkki

Title: $\quad$ Evaluating Heat Current through Concrete Crush for Heat Storing Application : a preliminary study using polynomial fitting for heat current curves

Year: $\quad 2020$

Version: Final draft (post print, aam, accepted manuscript)

Copyright C2020 IEEE. Personal use of this material is permitted. Permission from IEEE must be obtained for all other uses, in any current or future media, including reprinting/republishing this material for advertising or promotional purposes, creating new collective works, for resale or redistribution to servers or lists, or reuse of any copyrighted component of this work in other works.

Please cite the original version:

Martinkauppi, J. B., \& Hiltunen, E., Evaluating Heat Current through Concrete Crush for Heat Storing Application : a preliminary study using polynomial fitting for heat current curves. In: 2019 8th International Conference on Renewable Energy Research and Applications (ICRERA), Brasov, Romania, 2019 (pp. 392-396). https://doi.org/10.1109/

ICRERA47325.2019.8996815 


\title{
Evaluating heat current through concrete crush for heat storing application
}

\author{
A preliminary study using polynomial fitting for heat current curves
}

\author{
J.B. Martinkauppi, E. Hiltunen \\ School of Technology and Innovations \\ University of Vaasa \\ Vaasa, Finland
}

\begin{abstract}
The purpose of this paper is to study heat current through concrete crush as the crush is considered a possible material for heat storage. The heat current parameter is important for heat storages as it describes how material behaves as temperature changes in its environment. An experimental test is described for obtaining this parameter. Since the resulting data are noisy and have repetitive values, the heat current is evaluated with polynomial fitting.
\end{abstract}

Keywords-heat current, concrete crush, heat storage, polynomial fitting

\section{INTRODUCTION}

Heat current between different layers is very important factor for many applications. The layers can be e.g. from different materials or agglomerate sizes. Heat storage is naturally one possible application for which heat current is important. Heat current property of a material determines its capability to insulate or conduct heat.

Many materials have been naturally used for heat storages. Concrete is one of these materials, see e.g. [1-2]. Therefore, it would be naturally to study also concrete crush for this purpose [3]. In the earlier paper, other parameters like specific heat capacity was evaluated for [3]. This paper extends the evaluation of concrete crush for heat storages with heat current parameter. The experimental part for heat current evaluation is described more detail in report [4] (in Finnish).

It is important to study possible new applications for concrete crush as a lot of it is produced every year with a clear need for recycling. Concrete crush is European Union's largest waste stream (European commission, "EU Construction and Demolition Waste Protocol", which can be found at webpage https:/ec.europa.eu/growth/content/eu-constructionand-

demolition-waste-protocol-0_el) . It is also important to determine the effect of agglomerate size of concrete crush for heat storages as smaller agglomerates are more expensive to produce.

Naturally heat current is already studied for different aspects of solid concrete and its applications: Wang et al. studied heat transfer caused by surrounding climate conditions (e.g. solar, wind or rain) for high-permeable concrete pavement and its boundary conditions of heat related simulations [5]. Concrete with different properties have been examined by many authors, e.g. [6-7] and different models [8-9]. A review can be found in [10]. Concrete has been used also as a plate collector [11] and absorber plate [12]. Heat current and heat transfer are important for many applications (see e.g. [13][15]). However, here the focus is on testing a method for evaluating heat current for concrete crush.

In this paper, a short review of heat current based on typical physical models is made in Chapter II. This provides a background for understanding behavior of heat current for materials. In the Chapter III, a description is provided for collecting data under laboratory conditions. The collected temperature data is noisy and nonideal thus data processing is needed. Chapter IV describes this . The conclusions are drawn in Chapter V.

\section{THEORY}

\section{A. Heat current}

The heat current will go through different material layers (Fig. 1). It is assumed in this common, simple model that most of the current does not flow outside the layers. The temperatures are changing during the heating (dynamic state). Different layers will achieve the same temperature at the static state.

\begin{tabular}{|c|}
\hline Layer 1 \\
\hline Layer 2 \\
\hline Layer 3 \\
\hline 3 \\
\hline Layer $\mathrm{N}$ \\
\hline
\end{tabular}

Figure 1. A common, simple model present an idealization of heat current going through different material layers. Temperatures $T_{1} \ldots T_{\mathrm{N}}$ presents values measured at different layers. 
We assume that heat transfer between different layers of materials and boundaries inside the plastic tub happens via conduction. This is quite reasonable assumption as there is no material flow between layers and the heat transfer due to radiation should be minimum due to materials.

The common formula for heat current $H$ is given as

$$
H=k A \Delta T / L, \text { where }
$$

$k$ is thermal conductivity of material (constant), $A$ is the cross-sectional areas, $L$ is the lengths and $\Delta T$ is the temperature difference.

Equation (1) indicates that the heat current through one point or layer depends only on the temperature difference change during time at that point. To study the heat transfer differences between varying agglomerate sizes of concrete crush, the temperature difference needs to be normalized with maximum difference as shown in (2):

$$
\delta=(\Delta T) /\left(\Delta T_{\max }\right)
$$

where $\delta$ is the temperature difference ratio. The normalization scales all temperatures at range which maximum value is 1 .

\section{B. Polynomial fitting}

The original data was divided into two parts: heating and cooling. A second-degree polynomial was fitted for both part. The general formula for this polynomial is

$$
y=a x^{2}+b x+c,
$$

where $y$ is the value of polynomial, $x$ is a measurement point, and $a, b$ and $c$ are constants to be determined.

\section{EXPERIMENTAL DATA}

\section{A. Description of experiment}

The plastic tub was filled with different agglomerates. A steel net was first put in the bottom (Fig. 2 (a)), after it a rod with 22 temperature sensors (black rod in the middle of tub, the black wrapping was put to protect sensors) and heating cable (constant power $40 \mathrm{~W}$ ) were added as shown in Fig. 2 (b). Figs. 2 (c)-(e) shows layers with different agglomerate sizes and Fig. 2 (f) show example of fabric inserted between layers. The fabric was inserted to prevent mixing between different agglomerate layers.

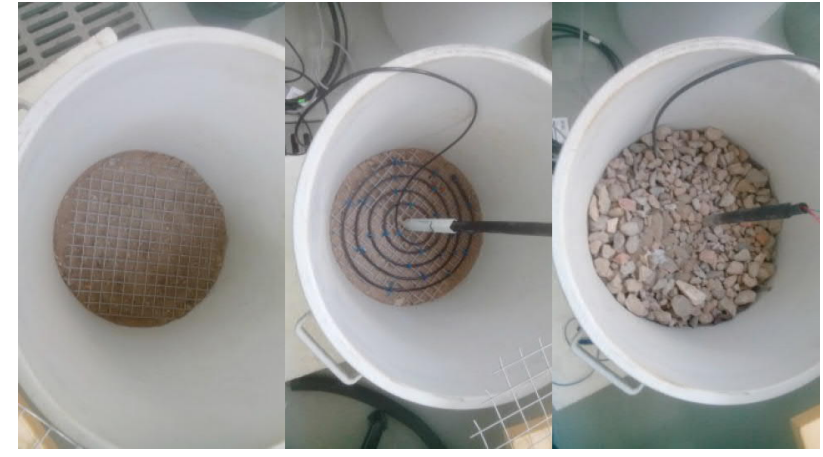

(a)

(b)

(c)

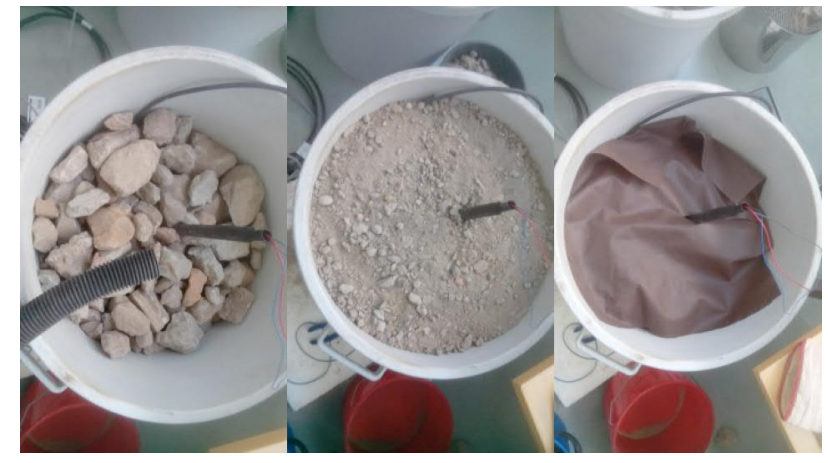

(d)

(e)

(f)

Figure 2. (a)-(f) different layers were added inside the plastic tube.

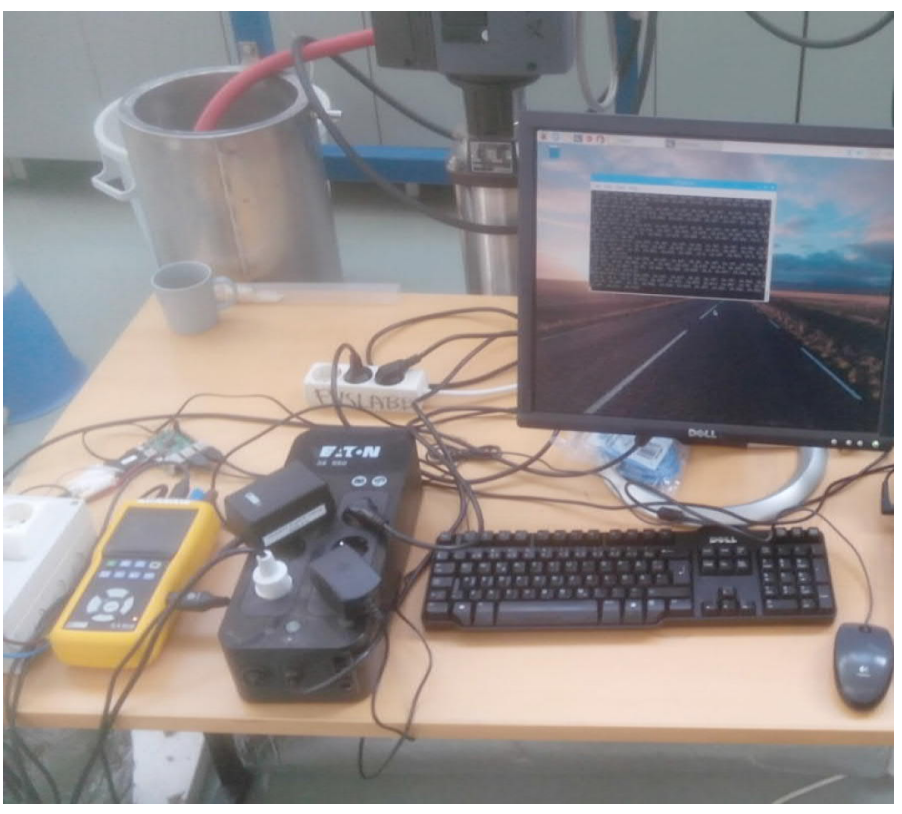

Figure 3. The measurement system.

The measurement system itself is displayed in Fig. 3. It consisted of Raspberry (with keyboard and display) connected and reading the sensors data, electric power meter C.A.8320. The program was made with Python. 


\section{B. Original data}

Fig. 4 present the original measurement data. Different material layers are indicated in the figure. The shape of heating and cooling resembles typical one for this kind of measurements.

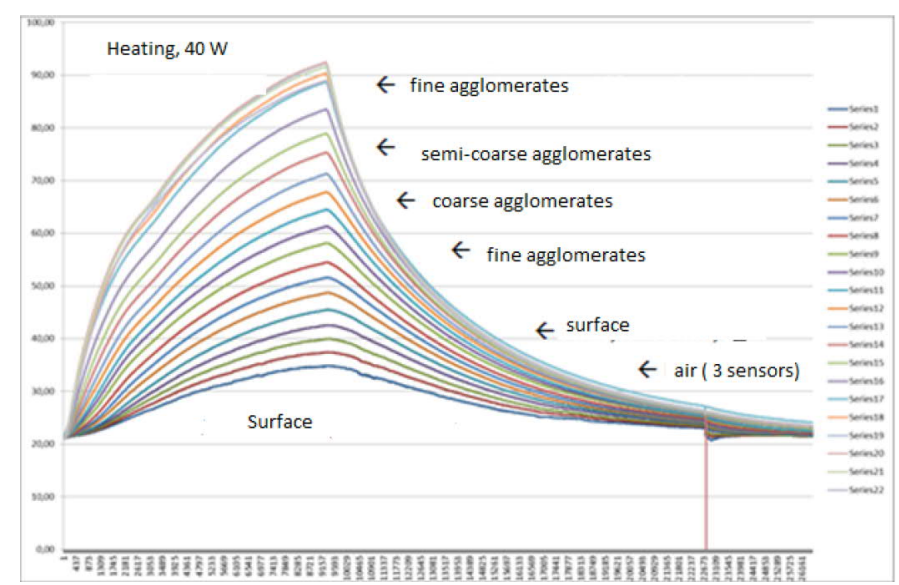

Figure 4. The original measurement data.

The data itself contains noise and repetitive values. These can be due to many reasons: sensor properties (e.g. slow to react the temperature change or too fast reading speed), heating can be a slow process, and so on.

Due to the properties of data, applying (1) and (2) will produce spurious output values. Smoothing of data or averaging spurious values are, of course, possible choices. However, the data resembles polynomials of second order. The polynomials itself are naturally easier to analyze mathematically.

\section{RESULTS}

The second order polynomial was fitted for all three cases, fine (Fig. 5), semi-coarse (Fig. 6) and coarse agglomerates (Fig. 7). The data was divided into two parts: heating, and cooling. The cooling was allowed happen naturally while the heating was forced.

Second order polynomials provide quite good match for the original heating and cooling curve data. The numerical values for polynomial coefficients are shown in Table 1 . The constant $a$ has small values - probably due to the number of measurement points. The heating and cooling parts have also different coefficients which might be caused difference between natural cooling and forced heating. Different agglomerate layers also have different coefficients.

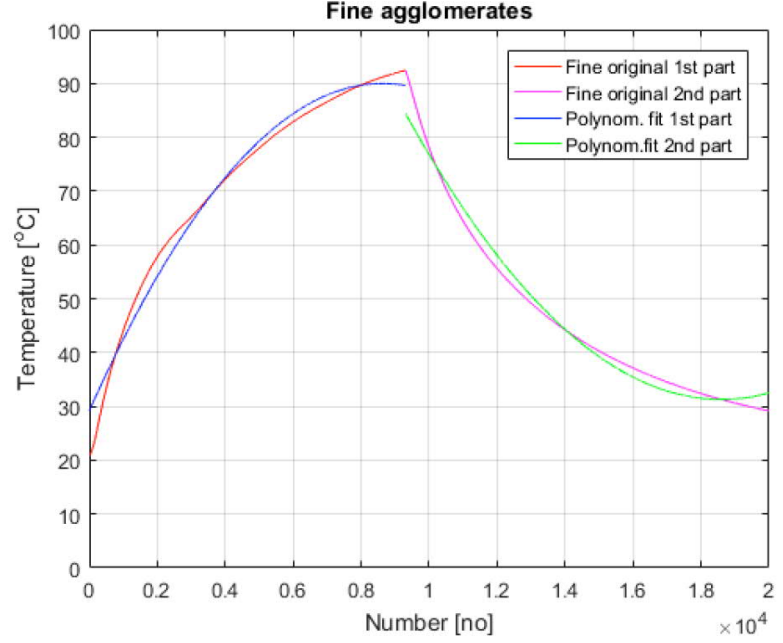

Figure 5. Original measurement data and its polynomial fit for fine agglomerates.

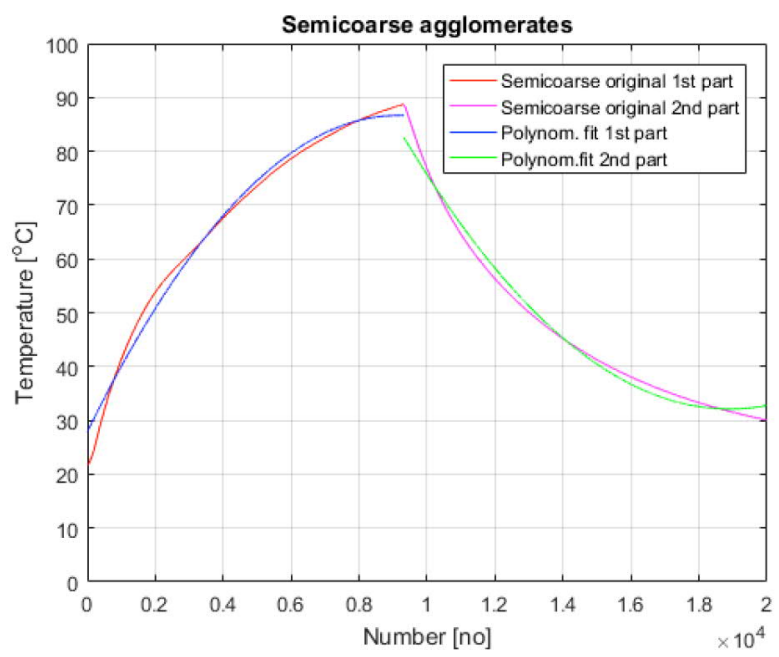

Figure 6. Original measurement data and its polynomial fit for semi-coarse agglomerates.

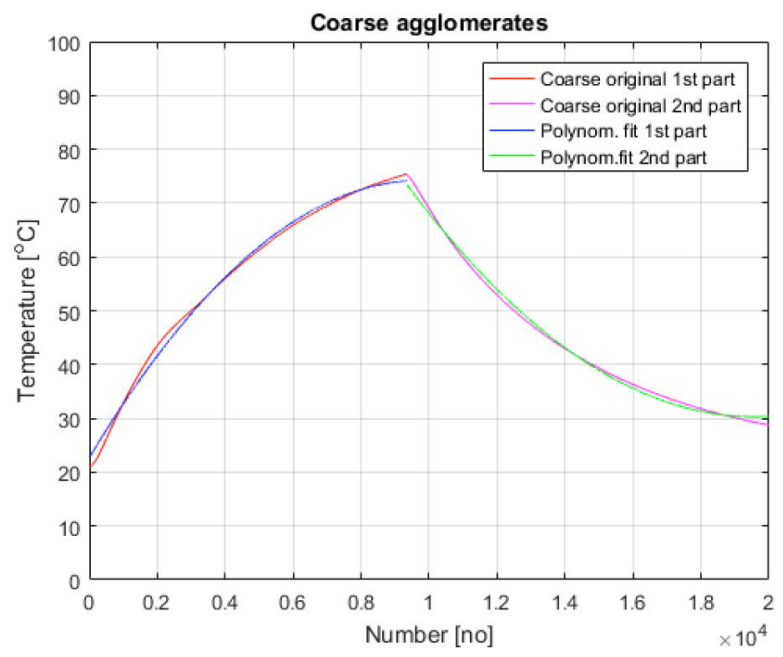

Figure 7. Original measurement data and its polynomial fit for semi-coarse agglomerates. 
Table 1. Polynomial coefficient

\begin{tabular}{|l|l|l|l|}
\hline $\begin{array}{l}\text { Polynomial } \\
\text { coefficient }\end{array}$ & $\begin{array}{l}2^{\text {nd }} \text { order } \\
(\text { constant } a)\end{array}$ & $\begin{array}{l}1^{\text {st }} \text { order } \\
(\text { constant } b)\end{array}$ & $\begin{array}{l}0^{\text {th }} \text { order } \\
(\text { constant } c)\end{array}$ \\
\hline Fine heating & $-8.1857 \mathrm{e}-07$ & 0.0141 & 29.1981 \\
\hline Fine cooling & $6.1536 \mathrm{e}-07$ & -0.0114 & 84.4598 \\
\hline Semicoarse & $-7.0323 \mathrm{e}-07$ & 0.0129 & 27.8551 \\
\hline $\begin{array}{l}\text { Semicoarse } \\
\text { cooling }\end{array}$ & $5.5030 \mathrm{e}-07$ & -0.0105 & 82.6268 \\
\hline Coarse heat & $-5.3774 \mathrm{e}-07$ & 0.0105 & 22.7082 \\
\hline Coarse cool & $4.1111 \mathrm{e}-04$ & -0.0084 & 73.4530 \\
\hline
\end{tabular}

The difference between temperatures can be calculated by differentiating polynomials. The results are shown in Fig. 8 and numerical values in Table 2.

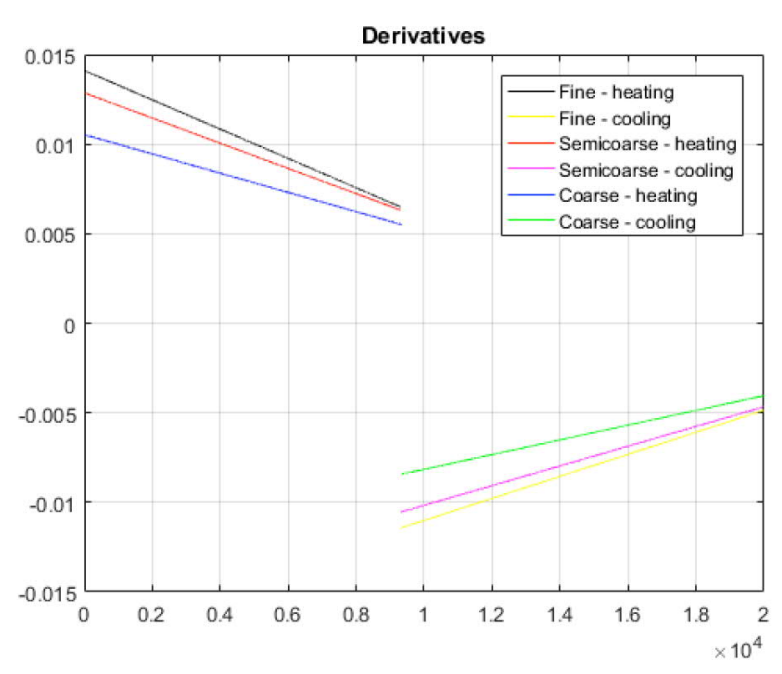

Figure 8 . Derivates of the polynomials.

Table 2. Mean and standard deviation of derivates

\begin{tabular}{|l|l|l|l|l|}
\hline Type & $\begin{array}{l}\text { Mean } \\
\text { heating }\end{array}$ & $\begin{array}{l}\text { Std } \\
\text { heating }\end{array}$ & $\begin{array}{l}\text { Mean } \\
\text { cooling }\end{array}$ & $\begin{array}{l}\text { Mean - } \\
\text { cooling }\end{array}$ \\
\hline Fine & 0.0103 & 0.0022 & -0.0081 & 0.0019 \\
\hline Semicoarse & 0.0096 & 0.0019 & -0.0076 & 0.0017 \\
\hline Coarse & 0.0080 & 0.0014 & -0.0062 & 0.0013 \\
\hline
\end{tabular}

The results after normalization using (2) are shown in Fig. 9 and Table 3.

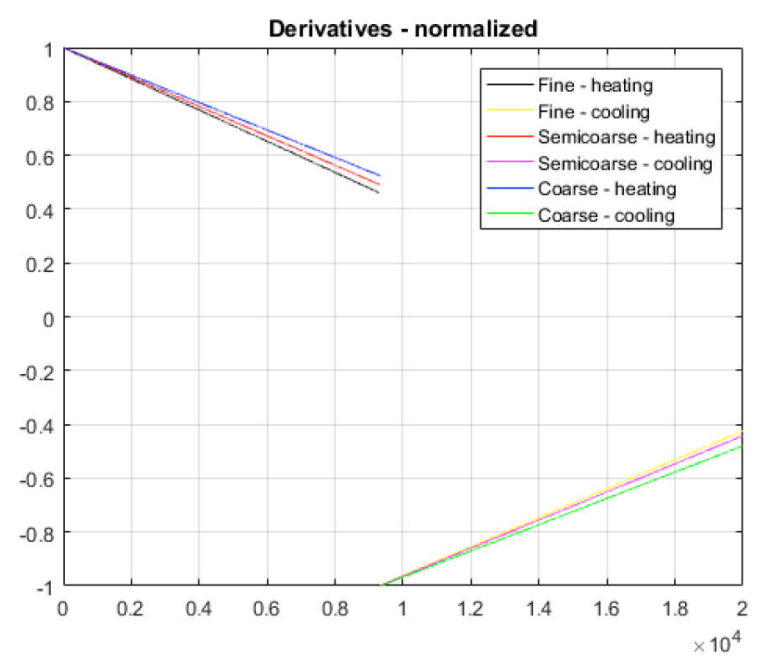

Table 3. Mean and standard deviation of derivates normalized

\begin{tabular}{|l|l|l|l|l|}
\hline Type & $\begin{array}{l}\text { Mean } \\
\text { heating }\end{array}$ & $\begin{array}{l}\text { Std } \\
\text { heating }\end{array}$ & $\begin{array}{l}\text { Mean } \\
\text { cooling }\end{array}$ & $\begin{array}{l}\text { Mean - } \\
\text { cooling }\end{array}$ \\
\hline Fine & 0.0111 & 0.0024 & -0.0088 & 0.0021 \\
\hline Semicoarse & 0.0108 & 0.0021 & -0.0086 & 0.0019 \\
\hline Coarse & 0.0106 & 0.0019 & -0.0083 & 0.0017 \\
\hline
\end{tabular}

\section{CONCLUSIONS}

A lot of concrete crush is produced all over the world but there is not so many possible re-uses of it. Thus new, possible uses need to be studied.

One of the possible applications is to use concrete crush as part of heat storage. The heat current is useful parameter when evaluating the potential of material for the storage.

In this paper, a preliminary test was made for heat current evaluation. Due to data quality, a polynomial fitting was needed. The preliminary results suggest that there can be difference in heat current behavior of different agglomerate sizes.

\section{ACKNOWLEDGEMENT}

The data used here was collected for a project funded by Regional Development fund (EAKR, code A73562) 1.1.31.8.2018. We express our gratitude for Regional Counsil of Ostrobothnia and two local companies. We like to thank Ms. A. Mäkiranta and Mr. T. Syrjälä for their role in making measurements and collecting data.

\section{REFERENCES}

[1] Doerte Laing, Dorothea Lehmann, Michael Fiß and Carsten Bahl, "Test Results of Concrete Thermal Energy Storage for Parabolic Trough Power Plants", J. Sol. Energy Eng., Vol. 131(4), 2009. 
[2] Rad, F. M., \& Fung, A. S. (2016). Solar community heating and cooling system with borehole thermal energy storage-review of systems. Renewable and Sustainable Energy Reviews, 60, 1550-1561.

[3] J.B. Martinkauppi, T. Syrjälä, A. Mäkiranta, and E. Hiltunen (2018), "Some Aspects of Recycling Concrete Crush for Thermal Heat Storage", 7th International Conference on Renewable Energy Research and Applications (ICRERA).

[4] J.B. Martinkauppi, T. Syrjälä, H. Haq, A. Mäkiranta, E. Hiltunen (2018) "Betonimurskeen uusiokäytettävyyden tutkiminen lämpövarastoinnissa", Report (in Finnish).

[5] Wang, C. F., Ji, D. B., Yi, Z. Q., \& Liu, L. (2011). Analysis of HighPermeable Concrete Pavement Heat Transfer Mechanism. In Advanced Materials Research (Vol. 168, pp. 859-863). Trans Tech Publications

[6] Chen, J., Wang, H., \& Li, L. (2015). Determination of effective thermal conductivity of asphalt concrete with random aggregate microstructure. Journal of Materials in Civil Engineering, 27(12), 04015045.

[7] Borhan, T. M. (2015). Effect of using recycled lightweight aggregate on the properties of concrete. Journal of University of Babylon, 23(2), 453-464.

[8] Isgor, O. B., \& Razaqpur, A. G. (2004). Finite element modeling of coupled heat transfer, moisture transport and carbonation processes in concrete structures. Cement and Concrete Composites, 26(1), 57-73.

[9] Chen, J., Wang, H., Xie, P., \& Najm, H. (2019). Analysis of thermal conductivity of porous concrete using laboratory measurements and microstructure models. Construction and Building Materials, 218, 90-98
[10] Asadi, I., Shafigh, P., Hassan, Z. F. B. A., \& Mahyuddin, N. B. (2018). Thermal conductivity of concrete-A review. Journal of Building Engineering, 20, 81-93.

[11] Sable, A. (2017). Effect of dimples on solar concrete plate collectors and its comparison with other domestic water heating systems. International Journal of Renewable Energy Research, 7(2), 660-667.

[12] Patil, S. R., Keste, A. A., \& Sable, A. B. (2016). Investigation and development of liquid flat plate solar collector using concrete as absorber plate and its performance testing. International Journal of Renewable Energy Research (IJRER), 6(4), 1212-1220.

[13] Haidar, C., Boutarfa, R., \& Harmand, S. (2019). Fluid Flow and Convective Heat Transfer Analysis on a Rotor of Wind Turbine Alternator with an Impinging Jet. International Journal of Renewable Energy Research (IJRER), 9(3), 1144-1153

[14] Pandey, S. N. (2016). A Three-dimensional Coupled Thermo-hydro Model for Enhanced Geothermal Systems. International Journal of Renewable Energy Research, 6, 1516-1523.

[15] Khaled, T., Fouad, K., Abdelkrim, K., Ismail, T., \& Hafsia, H. (2016). A Three-Dimensional Modeling of Photovoltaic Thermal Collector International Journal of Renewable Energy Research (IJRER), 6(2), 384-391 